\title{
Tumorigenic Conversion of p53-deficient Colon Epithelial Cells by an Activated Ki-ras Gene
}

\author{
Cinzia Sevignani, ${ }^{\star \S}$ Pawel Wlodarski, ${ }^{\star}$ Julie Kirillova, ${ }^{\star}$ W. Edward Mercer, ${ }^{\star}$ Keith G. Danielson, ${ }^{\ddagger}$ Renato V. Iozzo, ${ }^{\star \ddagger}$ \\ and Bruno Calabretta*\$ \\ $*$ Department of Microbiology and Immunology and ${ }^{\ddagger}$ Department of Pathology, Anatomy, and Cell Biology, Kimmel Cancer Center, \\ Jefferson Medical College, Philadelphia, Pennsylvania 19107; and ${ }^{\S}$ Department of Biomedical Sciences, University of Modena Medical \\ School, Modena, Italy
}

\begin{abstract}
Distinct genetic abnormalities (loss-of-function mutations of APC and p53 and oncogenic activation of Ki-ras) are associated with specific stages of the sporadic, most common types of colorectal tumors. However, the inability to maintain primary colon epithelial cells in culture has hindered the analysis of the pathogenetic role of these abnormalities in colorectal tumorigenesis. We have now established primary cultures of epithelial cells from the colon crypts of p53-deficient mice; these cells are nontumorigenic as indicated by their failure to form colonies in soft agar and to grow as tumors in immunodeficient SCID mice and in immunocompetent syngeneic hosts. Upon ectopic expression of an activated Ki-ras gene, p53-deficient colon epithelial cells form colonies in soft agar and highly invasive subcutaneous tumors in both immunodeficient and immunocompetent mice. Ectopic expression of wild-type p53, but not of a DNA-binding-deficient mutant, markedly suppressed the colony-forming ability of the Ki-ras-transformed p53-deficient epithelial cells. Together, these findings establish a functional synergism in colorectal tumorigenesis dependent on the effects of an oncogenic Ki-ras in a p53-deficient background. This model of tumorigenic conversion of colon epithelial cells might be useful to identify genetic changes associated with disease progression and to evaluate the therapeutic response to conventional and novel anticancer drugs. (J. Clin. Invest. 1998. 101:1572-1580.) Key words: oncogene $\bullet$ antioncogene $\bullet$ cell cultures $\bullet$ tumorigenesis
\end{abstract}

\section{Introduction}

The genetic alterations associated with initiation and progression of colorectal cancer are well-defined and have provided a paradigm for the multistep nature of cancer development (1,

Address correspondence to Dr. Bruno Calabretta, Department of Microbiology and Immunology, Kimmel Cancer Institute, Bluemle Life Sciences Building, Room 630, 233 South 10th Street, Philadelphia, PA 19107. Phone: 215-503-4522; FAX: 215-923-0249; E-mail: B_Calabretta@lac.jci.tju.edu Pawel Wlodarski is on a leave of absence from the Department of Histology, Warsaw Medical School, Poland.

Received for publication 13 June 1997 and accepted in revised form 6 February 1998.

J. Clin. Invest.

(C) The American Society for Clinical Investigation, Inc. 0021-9738/98/04/1572/09 \$2.00

Volume 101, Number 8, April 1998, 1572-1580

http://www.jci.org
2). However, the inability to maintain normal colorectal epithelial cells in culture has hampered the assessment of the oncogenic potential of the various genetic abnormalities identified in primary tumors or in tumor-derived cell lines. The colonic mucosa has proved difficult to study because this tissue is often heavily contaminated by bacteria and fungi and because the proliferative cells constitute a single layer lying deep in the crypts of Leiberkuhn. Despite attempts to develop longterm cultures of colonic epithelial cells from different species (3-5), proliferation of these cells has not been demonstrated for more than a few days $(6,7)$. There have been attempts to immortalize or transform intestinal epithelial cells by using known immortalizing viral proteins (8). For example, conditionally immortalized epithelial cell lines have been obtained from the colon of transgenic mice bearing a temperature-sensitive mutation of the simian virus 40 large tumor antigen gene (9). To overcome the difficulties of culturing normal colonic mucosal cells in vitro and to establish a long-term culture, we used tissues derived from young mice harboring an homozygous disruption of the p53 gene. These mice develop spontaneous lymphomas with high frequency before reaching the age of 6 mo, but not colon cancer or other types of carcinomas (10). Mutation of p53 is a common genetic abnormality acquired late in the development of colorectal cancer, and it is often detected in tumors carrying activating mutations of the Ki-ras oncogene (1). Nevertheless, it is not an absolute requirement that the genetic changes leading to colorectal cancer occur in a sequential order (1). Moreover, suppression of colorectal cancer cell growth can be achieved by inhibiting the expression of activated oncogenes (11) or by restoring the function of tumor suppressor genes $(12,13)$, without the hierarchy of effects that might be expected on the basis of a preferred order of appearance of genetic changes.

In this study, we induced tumorigenic conversion of colon epithelial cells from p53-deficient mice by retroviral-mediated introduction of an oncogenic Ki-ras mutant (14). After infection with the activated Ki-ras, neoplastic conversion of p53-deficient epithelial cells was readily obtained and the Ki-ras-transformed cells produced tumors in mice resembling colorectal cancer. These data lend support to the pathogenetic role of p53 and RAS mutations in colorectal cancer. Moreover, this model of colorectal cancer that depends on two defined events (loss of p53 function and expression of an activated Ki-ras gene) is well-suited for the assessment of novel antitumor therapeutic strategies.

\section{Methods}

Mice. Seven p53 knock-out (four female, three male) and four p53 $+/-$ (two female, two male) mice 8-12 wk old were used to generate cultures of primary colon epithelial cells and derivatives after infection with the Ki-ras-containing retrovirus (see below). Genotyping of the mice was carried out by standard methods of genomic DNA isola- 
tion from the tails of 1-mo-old mice, followed by PCR amplification of the wild-type $(\mathrm{p} 53+/+)$ or the knock-out (p53-/-) allele with specific primers as described (15).

Crypt isolation and culture techniques. Crypts were isolated from colonic intestinal mucosa by using a nonenzymatic technique (6). Briefly, the colon was removed from 8-12-wk-old mice and flushed with $0.1 \mathrm{M}$ calcium-magnesium free PBS to remove soiling. The colon was opened by longitudinal incision, soaked in $0.04 \%$ sodium hypochlorite for $30 \mathrm{~min}$ to kill bacteria and fungi, washed three times in PBS, cut into small pieces $\sim 0.5 \times 1.5 \mathrm{~mm}$, and placed in a tube with $20 \mathrm{ml}$ of PBS containing $1 \mathrm{mM}$ EDTA, $1 \mathrm{mM}$ EGTA, and $0.5 \mathrm{mM}$ DDT. After incubation at room temperature for 90 min with occasional shaking, the solution was removed carefully and replaced with PBS. The tube with the organ was vigorously shaken to detach the crypts from the underlying stroma until the majority of the crypts was released. All collected crypts were pooled and suspended in DME/ nutrient mixture F-12 (HAM) supplemented with $10 \%$ FCS (GIBCO BRL, Gaithersburg, MD), $2 \mathrm{mM}$ glutamine, $50 \mu \mathrm{g} / \mathrm{ml}$ penicillin/streptomycin, $10 \%$ conditioned medium from 48 -h cultures of the mouse rectum carcinoma cell line CMT-93 (American Type Culture Collection, Rockville, MD), $1 \mathrm{mM}$ sodium pyruvate, $15 \mathrm{mM}$ Hepes [pH 7.5], $0.1 \mathrm{mM}$ nonessential amino acids, $20 \mu \mathrm{g} / \mathrm{ml} \mathrm{EGF,} 6 \mu \mathrm{g} / \mathrm{ml}$ insulin, 6 $\mu \mathrm{g} / \mathrm{ml}$ transferrin, $1 \mu \mathrm{g} / \mathrm{ml}$ hydrocortisone, $5 \mu \mathrm{g} / \mathrm{ml}$ cholera toxin, 0.05 $\mathrm{mM}$ 2-mercaptoethanol, and $10 \mu \mathrm{M}$ of the ICE inhibitor tetrapeptide YVAD added only in the early stages of the culture. The crypts were plated at a density of $\sim 250 \mathrm{crypts} / \mathrm{cm}^{2}$ into mouse collagen type IVcoated $25 \mathrm{~cm}^{2}$ flasks (Collaborative Biomedical Products, Bedford, MA) containing a feeder layer made of a 3:1 mix of NIH 3T3 fibroblasts and colon-derived fibroblasts from the same strain of the p53 knock-out mice, treated with $10 \mu \mathrm{g} / \mathrm{ml}$ mitomycin C. The crypts were allowed to settle overnight in a minimal volume of medium at $37^{\circ} \mathrm{C}$ in an atmosphere of $5 \% \mathrm{CO}_{2}$. After overnight incubation, the volume of the culture medium was increased to $5 \mathrm{ml}$. New feeder layer was added every week. When cells formed a clone with a diameter of $\sim 3$ $\mathrm{cm}$, the culture was trypsinized and transferred into two $35-\mathrm{mm}$ mouse collagen type IV-coated tissue culture dishes containing the feeder layer described above. Contaminating colon fibroblasts were removed from the culture using $0.25 \%$ trypsin, which selectively releases fibroblasts from the culture surface, leaving epithelial cells attached to the bottom of the dish. Some of the fibroblasts were also physically removed by scraping or by aspiration. All these procedures were repeated until only epithelial-like cells remained in the culture and no fibroblasts were seen under the microscope. The medium was changed every other day and cells were passaged when confluent. Early passages of the culture were split at 1:3. Fibroblasts were also obtained from the same colon by the primary explant culture technique. The cultures were tested for the presence of mycoplasma using an ELISA detection kit (Boehringer Mannheim Biochemicals, Indianapolis, IN).

Plasmid construct. The cDNA corresponding to the Ki-ras 2 transforming allele (glycine to valine substitution at the 12th amino acid of the RAS protein) present in the human colon carcinoma cell line SW480 (SW11-1) (14) was obtained from American Type Culture Collection. The Ki-ras2-containing plasmid SW11-1 was linearized by PstI and then Klenow-blunted. Thereafter, the linearized SW11-1 plasmid was BamHI-digested and the 1.1-kb Ki-ras2 cDNA was released, gel purified, and ligated into the pLXSN vector digested with EcoRI, blunted, and digested with BamHI. In the pLXSN vector (16), the expression of Ki-ras2 was under the control of the long terminal repeat of the M-MLV, while the expression of the NEO resistance gene was driven by the simian virus 40 early promoter. The cDNA of human wild-type p53 and the R248W mutant were obtained from B. Vogelstein (Johns Hopkins University School of Medicine, Baltimore, MD), and cloned into the HpaI site of the LXSP vector.

Preparation of viral stock. pLXSN/Ki-ras2 was electroporated into the GP+E86 packaging line (17) and ecotropic recombinant retrovirus-producing cells were obtained after 2-3 wk of selection in G418containing medium $(1 \mathrm{mg} / \mathrm{ml})$. Viral stock containing supernatants was collected $3 \mathrm{~d}$ after formation of $80 \%$ confluent monolayer in DME/F-12 (HAM) medium supplemented with $0.05 \mathrm{mM}$ 2-mercaptoethanol. Titers of the viral stocks were determined by infecting Rat-2 cells and scoring the number of G418-resistant colonies. The titer of the virus used in the experiments was $8 \times 10^{3} \mathrm{cfu} / \mathrm{ml}$.

Retroviral infection of p $53-/-$ epithelial cultures. A $70 \%$ confluent monolayer of primary epithelial cells (fifth passage) from colonic crypts was trypsinized, washed, and replated in the same $(60-\mathrm{mm})$ tissue culture dish. The next day, cells were infected with retroviral supernatants for $72 \mathrm{~h}$ in the presence of polybrene (Sigma Chemical Co., St. Louis, MO). The supernatants were changed every $6 \mathrm{~h}$ and the concentration of polybrene was $20 \mu \mathrm{g} / \mathrm{ml}$ for $12 \mathrm{~h}$ and $10 \mu \mathrm{g} / \mathrm{ml}$ for the next $12 \mathrm{~h}$ each day. After $72 \mathrm{~h}$, the supernatant was removed and replaced with culture medium for $24 \mathrm{~h}$. The next day, G418 (GIBCO BRL) was added at $1-2 \mathrm{mg} / \mathrm{ml}$, depending on the density of the monolayer. Uninfected p53 - /- cells died when G418 was added at a concentration $\geq 1 \mathrm{mg} / \mathrm{ml}$, despite bearing a $\mathrm{NEO}$ gene within each p53 allele. Fifth passage p53 knock-out fibroblasts derived from the colon explants were also infected with the same retrovirus. A $70 \%$ monolayer was trypsinized and replated in the same tissue culture dish $(35-\mathrm{mm})$. The next day, cells were infected with the viruscontaining supernatant for $48 \mathrm{~h}$ in the presence of $8 \mu \mathrm{g} / \mathrm{ml}$ polybrene (Sigma Chemical Co.). The supernatants were changed approximately every $6 \mathrm{~h}$. Clones of infected cells were selected by adding $\mathrm{G} 418$ at $1.5 \mathrm{mg} / \mathrm{ml}$. Integration of the $\mathrm{Ki}-\mathrm{RAS}-$ containing retrovirus was established by PCR amplification of genomic DNA using a $5^{\prime}$ primer (5' GCCTCGACTCTCCCTTTATCC $3^{\prime}$ ) located in the pLXSN vector upstream of the Ki-RAS insert and a $3^{\prime}$ primer $\left(5^{\prime}\right.$ GTCCTGAGCCTGTTTTGTGTC 3') corresponding to nucleotides 378-398 of the Ki-ras2 coding sequence (14).

Colony formation assays of Ki-ras-infected p53 -/- epithelial cells. Cells (14th passage) were seeded at a density of $7.5 \times 10^{5} / 100$ $\mathrm{mm}$ petri dishes in duplicate. Cells were grown for $16 \mathrm{~h}$ in DME/nutrient mixture F-12 (HAM) (GIBCO BRL) supplemented with $10 \%$ FCS (Sigma Chemical Co.), $1 \mathrm{mM}$ sodium pyruvate (Sigma Chemical Co.), $15 \mathrm{mM}$ Hepes (GIBCO BRL), $0.1 \mathrm{mM}$ nonessential amino acids (GIBCO BRL), $10 \mathrm{ng} / \mathrm{ml}$ EGF (Sigma Chemical Co.), $3 \mu \mathrm{g} / \mathrm{ml}$ insulin (Sigma Chemical Co.), $3 \mu \mathrm{g} / \mathrm{ml}$ transferrin (Sigma Chemical Co.), 0.5 $\mu \mathrm{g} / \mathrm{ml}$ hydrocortisone (Sigma Chemical Co.), $2.5 \mu \mathrm{g} / \mathrm{ml}$ cholera toxin (Sigma Chemical Co.), $0.1 \mathrm{ng} / \mathrm{ml}$ triiodothyronine (Sigma Chemical Co.), and $0.05 \mathrm{mM}$ 2-mercaptoethanol (GIBCO BRL). Cells were transfected by standard calcium phosphate precipitation (18) with $20 \mu \mathrm{g}$ each of wild-type or mutant (R248W) p53 cDNA. DNA precipitates were left on the cells for $12 \mathrm{~h}$. Cells were then washed with PBS and cultured in fresh media in the presence of puromycin $(3 \mu \mathrm{g} / \mathrm{ml})$ for 2 wk. Colonies were washed with PBS and stained with methylene blue in $50 \%$ methanol for $10 \mathrm{~min}$.

Ultrastructural studies of cells grown within collagen. For ultrastructural studies, control colonic epithelial cells and their retrovirally infected counterparts were cultured within a collagenous matrix essentially as described (19) with minor modifications. Bovine dermal collagen (Vitrogen $100,3 \mathrm{mg} / \mathrm{ml}$ ) dissolved in $0.012 \mathrm{~N} \mathrm{HCl}$ was purchased from Celtrix, Inc. (Santa Clara, CA). A collagen mix containing Vitrogen 100, 10\% 8× DME, and 4\% Matrigel (Collaborative Biomedical Products) was prepared and stored on ice. Each well of a 24-well plate was coated with $0.2 \mathrm{ml}$ of collagen gel mix and the plate was incubated at $37^{\circ} \mathrm{C}$ for $1 \mathrm{~h}$ to allow the collagen to gel. Approximately $3 \times 10^{5}$ cells were mixed with $0.2 \mathrm{ml}$ collagen mix and overlaid on a previously collagen-coated well. The cell suspension in collagen was allowed to gel for $1 \mathrm{~h}$ at $37^{\circ} \mathrm{C}$ and then $0.7 \mathrm{ml}$ medium was added to the culture. The medium was changed after $4 \mathrm{~h}$ and thereafter every $2 \mathrm{~d}$. After 5 or $6 \mathrm{~d}$ of incubation, the cultures were fixed with $2.5 \%$ ice-cold glutaraldehyde. The collagen gels could then be lifted out with a spatula and placed in a vial of fixative before processing for transmission electron microscopy (19).

Soft agar assays. Primary epithelial cell cultures (eighth passage) infected or noninfected with the Ki-ras retrovirus were harvested for agar cloning. The clonal agar culture was performed in a double-layer 

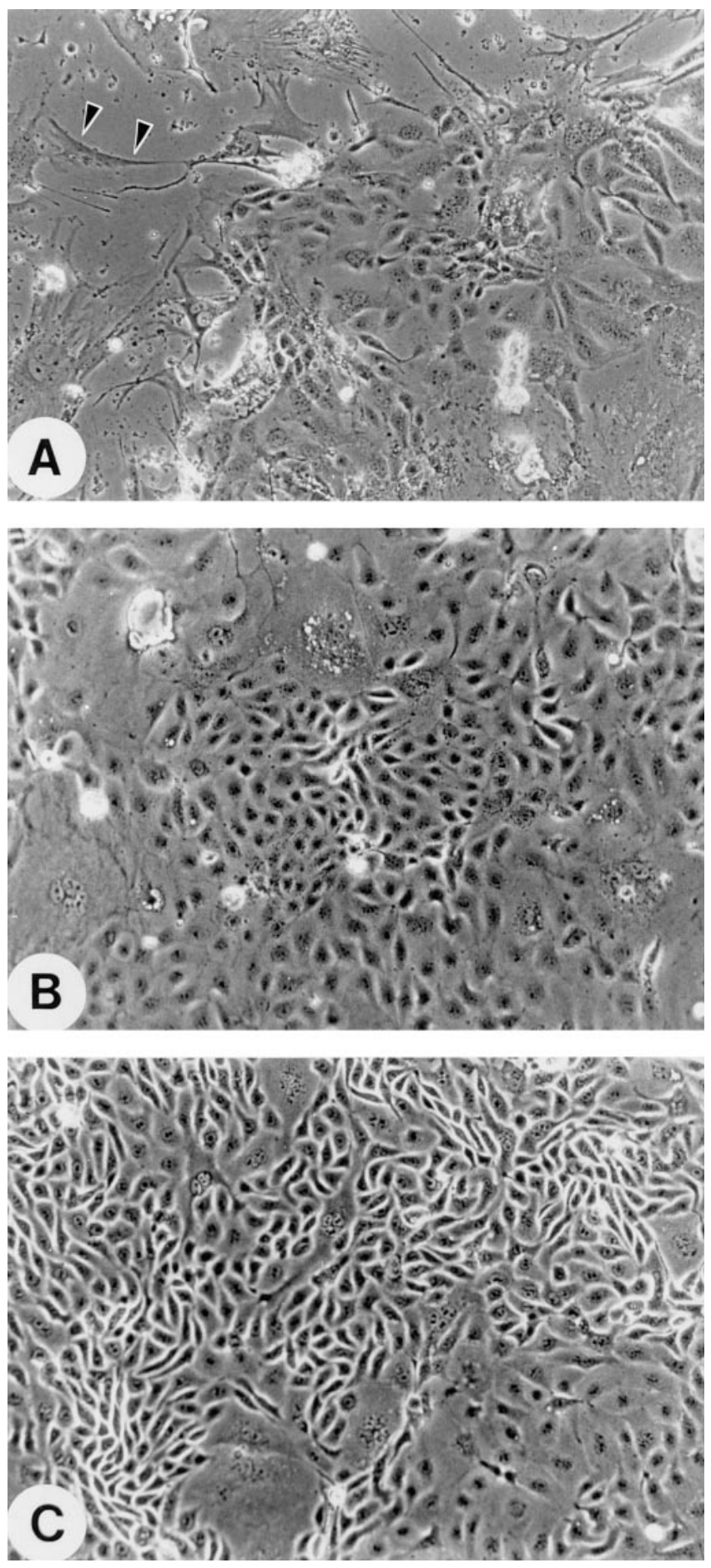

Figure 1. (A) Phase contrast of an 18-d epithelial colony from the colon of a p53 knock-out young adult female mouse. The epitheliallike cells are surrounded by the fibroblast feeder layer (arrowheads) of growth-arrested NIH 3T3 fibroblasts. Several multinucleate epithelial cells are visible on the right lower corner. $(B)$ p53 - / - colon epithelial cells at the 13th passage in monolayer culture, without the feeder layer of mitomycin C-treated NIH 3T3 fibroblasts. The culture shows heterogeneity of cell types with epithelial-like morphology. These cells have clear cytoplasm and oval clear nuclei with distinct nucleoli and multinucleate cells are always present in the culture. $(C)$ Ki-ras2-infected p53 -/- colon epithelial cells at the 13th passage showing a high number of elongated cells without other evident morphological features distinguishing these cells from the agar system. $1 \mathrm{ml}$ basal layer culture medium with a final $0.5 \%$ agarose (GIBCO BRL) concentration was prepared in $35-\mathrm{mm}^{2}$ plastic Petri dishes. Approximately $5 \times 10^{3} / \mathrm{ml}$ viable cells (five replicates) in $1 \mathrm{ml}$ upper layer medium $(0.2 \%$ agarose $)$ were overlaid onto the preformed basal layer. Dishes were incubated for $<21 \mathrm{~d}$ at $37^{\circ} \mathrm{C}$ in a humidified atmosphere of $5 \% \mathrm{CO}_{2}$. The colonies were sized with a calibrated eye-piece grid with the use of an Olympus CK2 inverted microscope at a magnification of 100 . Colonies with a diameter $\geq 125$ $\mu \mathrm{m}$ were counted after 1 and $2 \mathrm{wk}$.

Xenograft studies. Uninfected, LXSN-infected, and Ki-ras-infected p53 - / - colon epithelial cells (eighth passage) were inoculated $\left(10^{6}\right.$ cells in $150 \mu \mathrm{l}$ PBS) under the skin of both flanks of five Fox Chase ICR SCID ${ }^{\mathrm{TM}}$ outbred male mice [Tac:Icr:Ha(ICR)-scidfDF]. In a second experiment, 15 additional mice (5 mice in each group) were inoculated with $10^{6}$ infected and noninfected colon epithelial cells (11th passage). Five SCID mice were also inoculated with $10^{6}$ cells of the mouse rectum carcinoma line CMT-93. Tumor growth was assessed twice weekly by microcaliper measurement. Tumor tissue was fixed in $10 \%$ buffered formaldehyde and processed for routine histology (20).

RT-PCR detection of endogenous Ki-ras. Total RNA from p53 $-/-$ colon epithelial cell cultures (eighth passage) was reverse transcribed using M-MLV reverse transcriptase (GIBCO BRL), dNTPs, and random primers. The Ki-ras double-stranded cDNA was amplified by PCR using primers specific for both forms of Ki-ras mRNA generated by alternative splicing (21). The PCR products were subcloned into the pCR II vector (Invitrogen Corp., Carlsbad, CA) and sequenced. The primers used were: $5^{\prime}\left(5^{\prime}\right)$ GCCTGCTGAAAATGACTGAGT (3'), 3'A: (5') CAGATTACATTATAACGCATT (3'), 3'B: (5')TCACATAACTGTACACCTTGT (3'). The 5' primer is common for both Ki-RAS mRNA transcripts; primer $3^{\prime} \mathrm{A}$ corresponds to the $3^{\prime}$ end of exon $4 \mathrm{a}$, while primer $3^{\prime} \mathrm{B}$ corresponds to $3^{\prime}$ end of exon $4 \mathrm{~b}$.

Western blotting. $10^{6}$ cells obtained from each culture were lysed in lysing buffer (1\% NP-40, $0.15 \mathrm{NaCl}, 0.01 \mathrm{M}$ Hepes [pH 7.5], $10 \%$ glycerol) with proteinase inhibitors ( $1 \mathrm{mM} \mathrm{PMSF}, 10 \mu \mathrm{g} / \mathrm{ml}$ aprotinin, $10 \mu \mathrm{g} / \mathrm{ml}$ leupeptin, $1 \mathrm{mM}$ sodium orthovanadate, $0.5 \mathrm{mM}$ EDTA). Protein lysates were immunoprecipitated on Agarose coated with anti-H-Pan-ras antibody (Oncogene Science Inc., Manhasset, NY) and then run on $17.5 \%$ SDS-PAGE, transferred on nitrocellulose membrane (Schleicher \& Schuell, Keene, NH), and blocked as described (22). In the same experiments, when the total amount of proteins was $>100 \mu \mathrm{g}$, incubation with the Pan-ras ${ }^{\mathrm{Val}-12}$ antibody (Oncogene Science) followed by washing and incubation with the secondary antibody were according to manufacturer's protocols. Immunoreactivity was determined using the ECL kit (Amersham, Arlington Heights, IL).

\section{Results}

Establishment of epithelial cell cultures from crypts of p53 knock-out mice. During the first $48 \mathrm{~h}$ after the isolation of mouse colon crypts, epithelial cells surrounded by the fibroblast feeder layer attached to collagen type IV-coated plates. The majority of the attached cells died during the first 2-3 wk, and only a small number of cells continued to grow, but longterm primary cultures with epithelial-like morphology were reproducibly obtained when crypts of young p53 knock-out mice were used and the feeder layers were freshly prepared. The morphology of the cells was epithelial-like, with typical cuboi-

noninfected p53 colon epithelial cells. Photographs of epithelial colonies $(A-C)$ were taken at a magnification of 200 with an inverted phase-contrast microscope. 
dal shape (Fig. $1 A$ ). The epithelial-like cells could be readily distinguished from the slender fibroblasts of the feeder layer (Fig. $1 \mathrm{~A}$, arrowheads). They exhibited a cobblestone pattern typically observed in closely adhering cells (Fig. $1 \mathrm{~B}$ ). When the epithelial cells reached a high density, they were passaged on mouse collagen type IV- or rat tail collagen type I-coated dishes or flasks, in the absence of the fibroblast feeder layer. After nine passages in collagen type IV-coated plates, the cells could be grown routinely at lower density in regular tissue culture dishes or flasks (Fig. $1 \mathrm{~B}$ ). Most of the cells exhibited a clear cytoplasm and oval clear nuclei with distinct nucleoli. In addition, multinucleate cells were detectable among the monolayer cell culture. The epithelial nature of the cells was confirmed by immunostaining with a polyclonal Pancytokeratin antibody (data not shown). The histogenetic origin as colon epithelial cells of the primary culture was confirmed by transmission electron microscopy. The cultured cells formed anastomosing cords and tubelike structures (Fig. 2, $A$ and $B$ ) with pleomorphic lumina often lined by well-developed surface microvilli (Fig. 2 A, arrowheads). The cells exhibited tight junctions (Fig. $2 C$ ), prominent Golgi complexes and intermediate filaments (Fig. $2 \mathrm{D}$ ), and well-developed desmosomes (Fig. $2 E$ ). Tight junctions, also known as zonula occludens, are characteristically found on the boundary between epithelial cells near the luminal surface and form a continuous belt-like region of close membrane contacts encircling the apex of the cells (23). The presence of lumina sealed by tight junctions, the obvious polarization of the cells, and the presence of abundant microvilli unequivocally prove the epithelial nature of these cells.

Infection of p53-deficient colon epithelial cells with a retrovirus expressing an activated Ki-ras. Colon epithelial cell cultures established from the crypts of p53-deficient mice as described above were infected with the supernatant of GP-E86 packaging cells transfected with the retroviral vector carrying the activated $\mathrm{Ki}$-ras gene. Before infection with the Ki-ras retrovirus, RT-PCR amplification and sequencing of the endogenous Kiras mRNA revealed that the Ki-ras gene remained in the wildtype form in the p53 - /- colon epithelial cells (data not shown). After selection in G418-containing medium, mixed cell populations were expanded and assessed for retroviral integration and expression of mutant Ki-RAS (Fig. 3). As indi-
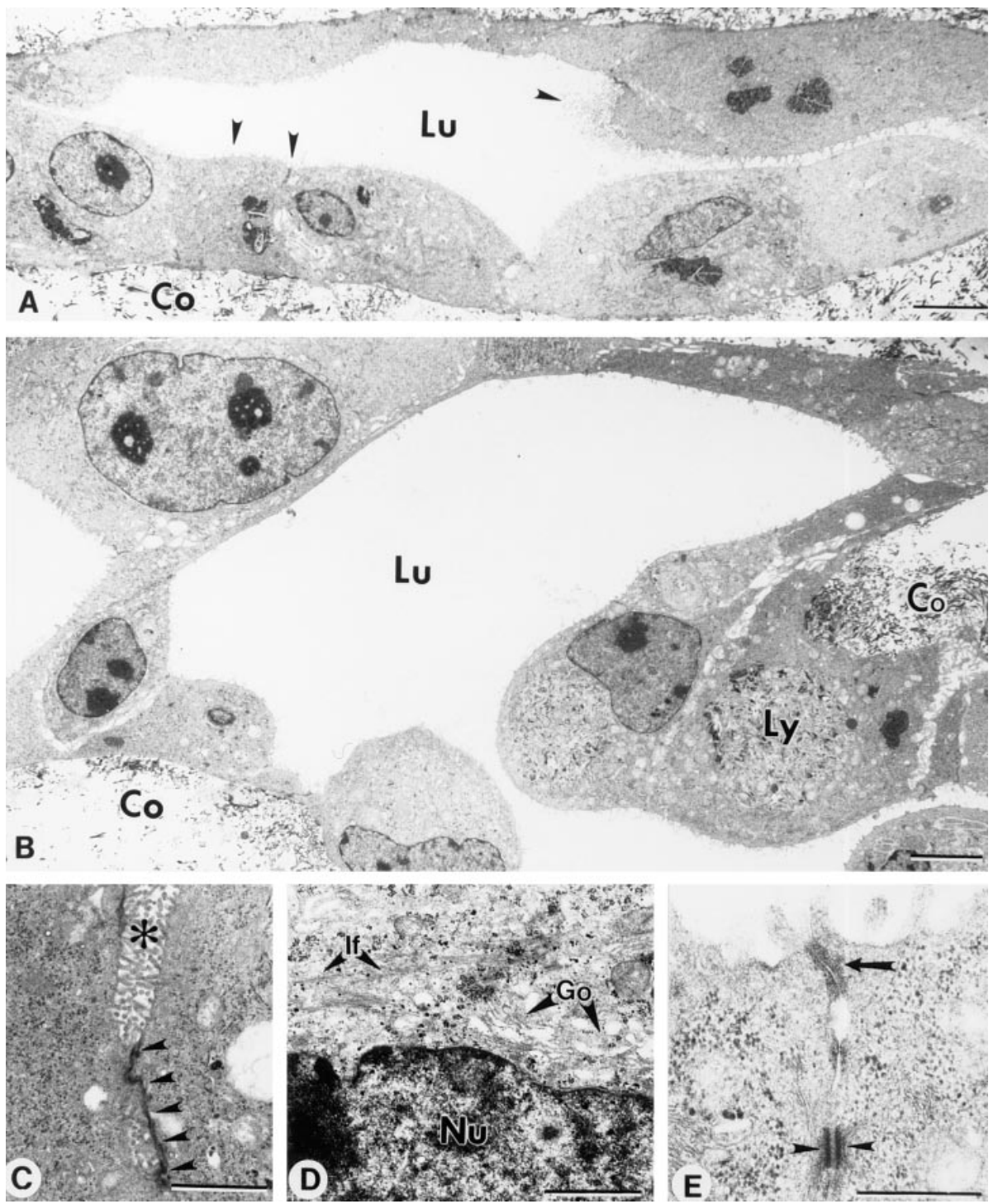

Figure 2. Gallery of transmission electron micrographs of p53-deficient colonic epithelial cells growing within a collagenous gel matrix. $A$ and $B$ are two representative low-power cross-sectional views of tube-like structures formed by the cells. Notice the presence of large lumina $(L u)$ lined by well-developed microvillar surface ( $A$, arrowheads). The cells are well-polarized with a basal surface facing the collagen ( $\mathrm{Co}$ ) matrix and an apical surface lined by microvilli. Notice the presence of multiple tight junctions ( $C$, arrowheads) in close association with microvilli ( $C$, asterisk), prominent Golgi complexes $(D, G o)$, bundles of intermediate filaments $(D, I f)$, a well-developed desmosome (macula adherens) ( $E$, arrowheads), followed from bottom to top by an intermediate junction (zonula adherens) and a tight junction (zonula occludens) (E, arrowheads). Bars in $A$ and $B=4 \mu \mathrm{m}$; in $C=2 \mu \mathrm{m}$; in $D=1 \mu \mathrm{m}$; in $E=0.5 \mu \mathrm{m}$. 
A

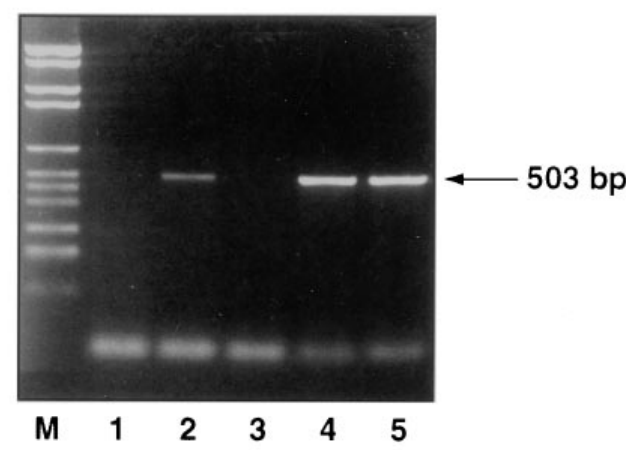

B

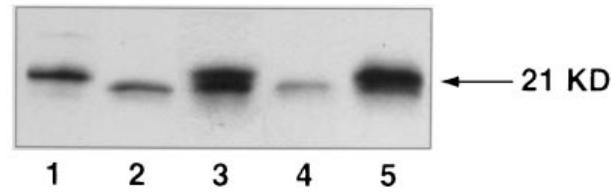

Figure 3. Genomic integration and expression of the pLXSN/Ki-ras2 construct. $(A) \mathrm{PCR}$ analysis for retroviral integration of mutant Kiras. Lanes are as follows: $M$, molecular weight marker III (Boehringer Mannheim Biochemicals); 1, p53 -/- colon epithelial cells; 2, Ki-ras-infected p53 -/- epithelial cells; 3, p53 -/- fibroblasts; 4, Kiras-infected p53 -/- fibroblasts; 5, pLXSN-Ki-ras2 vector. (B) Western blotting for p21 Ras expression. Lanes are as follows: 1, SW480 cells (human colon carcinoma) as positive control; 2, p53 -/- colon epithelial cells; 3, Ki-ras-infected p53 -/- colon epithelial cells; 4, p53 -/- colon fibroblasts; 5, Ki-ras-infected p53 -/- colon fibroblasts.

cated by PCR analysis using $5^{\prime}$ and $3^{\prime}$ primers located in the retroviral vector and in the Ki-ras insert, respectively, the p53deficient epithelial cells showed the product of PCR amplification expected in retrovirally infected cells (Fig. $3 A$ ). Moreover, expression of the mutant $\mathrm{Ki}$-ras protein was detected in the infected cells (Fig. $3 \mathrm{~B}$ ) by Western blot analysis with a monoclonal antibody [pan-RAS Val-12 (Ab-1); Oncogene Science] which distinguishes wild-type from mutant p21 RAS.

To determine whether the outgrowth of Ki-ras-infected p53 -/- epithelial cells was due to the expansion of a clonal or oligoclonal population of transformed cells, more than 50 "clones" were obtained by limiting dilution of a mixed cell population (10th passage) of Ki-ras-infected p53 -/- cells. When the clones reached a number in excess of $10^{6}$ cells, genomic DNA was isolated and, after digestion with the restriction enzyme BamHI, hybridized with a ${ }^{32} \mathrm{P}$-labeled fragment corresponding to the NEO cassette of the LXSN retroviral vector. A single band corresponding to the NEO-containing targeting vectors used to inactivate the endogenous p53 gene (10) was detected in p53-/- epithelial cells used as control (Fig. 4, lane 1); in marked contrast, the pattern of hybridizing bands in eight different clones from Ki-ras-infected p53 -/cells was rather heterogenous (Fig. 4, lanes 2-9), consistent with the outgrowth of multiple, independently transformed cells after infection of p53 -/- epithelial cells with the Ki-rascontaining retrovirus.

Morphological characteristics and growth properties of p53deficient, Ki-ras-infected colon epithelial cells. After infection with the Ki-ras 2 retroviral vector, the p $53-/-$ colon epithelial

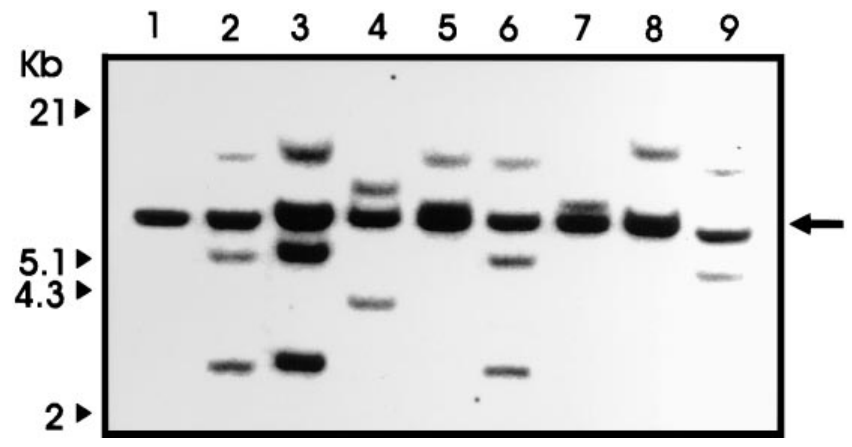

Figure 4. Integration of LXSN/Ki-ras in infected p53-/- colon epithelial cells. Genomic DNA $(15 \mu \mathrm{g})$ from p $53-/-$ epithelial cells and eight different clones of Ki-ras-infected cells was digested with BamHI restriction endonuclease, electrophoresed, blotted, and probed with a ${ }^{32} \mathrm{P}$-labeled $0.6-\mathrm{kb}$ PstI fragment complementary to the NEO cassette of the LXSN retroviral vector. The arrow indicates the endogenous NEO band (from the p53 targeting vector) in p53-/cells. Size (in $\mathrm{kb}$ ) of the molecular weight marker fragments is on the left.

cells exhibited morphological features very similar to those of the parental noninfected cells. However, a greater number of cells with an elongated appearance was detected in the population of Ki-ras-infected cells (Fig. $1 C$ ). Often the cells exhibited a more refractile appearance, a typical feature of rapidly growing tumor cells. To determine if there were differences in the growth properties of noninfected and Ki-ras-infected p53 $-/-$ colon epithelial cells, both cell types were assessed for proliferation in liquid culture and for colony formation in soft agar assays.

In three independent experiments, $10^{4}$ cells were plated in triplicate 6-well dishes and counted 2 and $4 \mathrm{~d}$ after plating. Kiras-infected cells grew more rapidly than the parental, noninfected cells (data not shown). Of greater importance, in five independent experiments assessing growth in soft agar, only the Ki-ras-infected cells formed numerous, large colonies (Table I). We also assessed the invasive properties of Ki-ras-expressing colon epithelial cells by plating $6 \times 10^{5}$ cells (parental, LXSN-infected, and Ki-ras-infected p53 -/- colon epithelial cells) into Biocoat ${ }^{\circledR}$ Matrigel $^{\circledR}$ invasion chambers containing an $8-\mu \mathrm{m}$ pore size membrane. $24 \mathrm{~h}$ after plating, the number

Table I. Soft Agar Colony Formation Assays Using Parental and Ki-ras-infected p53-/-Colon Epithelial Cells

\begin{tabular}{|c|c|c|c|}
\hline \multicolumn{2}{|c|}{ p53-/- epithelial cells } & \multicolumn{2}{|c|}{$\begin{array}{l}\text { p53 - /- epithelial cells } \\
\text { Ki-ras-infected }\end{array}$} \\
\hline $7 \mathrm{~d}$ & $14 \mathrm{~d}$ & $7 \mathrm{~d}$ & $14 c$ \\
\hline 0 & 0 & 20 & 35 \\
\hline 0 & 0 & 15 & 36 \\
\hline 0 & 0 & 12 & 34 \\
\hline 0 & 0 & 14 & 35 \\
\hline 0 & 0 & 16 & 36 \\
\hline
\end{tabular}

Parental and Ki-ras-infected p53 - /- epithelial cells were plated in 35mm-diameter plates (five for each cell type) at $5 \times 10^{3}$ cells $/ \mathrm{ml}$. Colonies with a diameter $\geq 125 \mu \mathrm{m}$ were counted after 1 and $2 \mathrm{wk}$. 
WTp53

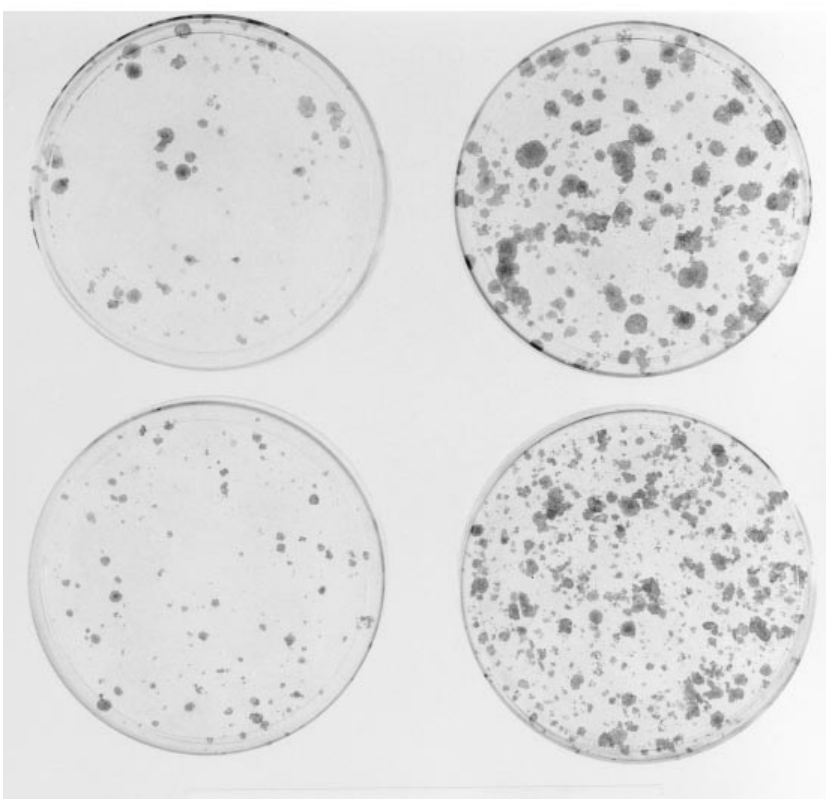

Figure 5. Colony formation of Ki-ras-infected p53 - /- cells transfected with wild-type or mutant p53. $48 \mathrm{~h}$ after transfection, $3 \times 10^{5}$ cells/plate were selected for $2 \mathrm{wk}$ in the presence of puromycin $(3 \mu \mathrm{g} / \mathrm{ml})$. The plates were fixed and stained with methylene blue in 50\% methanol for $10 \mathrm{~min}$. Colony formation efficiency after transfection with the empty vector was very similar to that with the R248W p53 mutant.

(triplicate experiment) of Ki-ras-infected p53 -/- colon epithelial cells on the lower surface of the membrane was four times that of control cells (data not shown).

To determine whether the transformation of Ki-ras-infected p53 - / cells was dependent on the loss of p53 function, we investigated whether ectopic expression of wild-type p53 would suppress the growth of Ki-ras-infected p53-/- cells. Wild-type p53 and the DNA binding deficient R248W mutant were cloned in a retroviral vector (LXSP) carrying the puromycin resistance gene and transfected into Ki-ras-infected p53 $-/-$ cells. After a 2-wk selection in puromycin, the number of puromycin-resistant colonies arising from wild-type p53-transfected cells was markedly diminished as compared with that derived from cultures transfected with the DNA binding deficient mutant (Fig. 5).

In vivo evaluation of tumor growth. The tumorigenic potential of parental p53-deficient epithelial cells or cells infected with the empty retroviral vector or with the mutant $\mathrm{Ki}$-ras gene was assessed by injecting $10^{6}$ cells subcutaneously in immunocompromised SCID mice (Table II) as well as in immunocompetent syngeneic mice (Table III). By day 14, all of the mice injected with p53-/- Ki-ras-infected cells produced subcutaneous tumors, whereas tumors were not detected in mice injected with parental or LXSN-infected p53-1- epithelial cells (Tables II and III). Of note, tumor formation from p53 - / - Ki-ras-infected cells was more rapid than that from the tumorigenic CMT-93 murine line used as positive control (data not shown). Histological analysis of the tumor xenografts produced by cells expressing the oncogenic Ki-ras exhibited
Table II. Evaluation of Tumor Growth in SCID Mice

\begin{tabular}{|c|c|c|c|c|}
\hline \multirow{2}{*}{$\begin{array}{l}\text { p53-/- colon } \\
\text { epithelial cells }\end{array}$} & \multicolumn{2}{|c|}{$\begin{array}{l}\text { Tumor incidence using } \\
\text { cells from the } 8 \text { th } \\
\text { and 11th passages }\end{array}$} & \multirow{2}{*}{$\begin{array}{l}\text { Latency } \\
\text { time }\end{array}$} & \multirow{2}{*}{$\begin{array}{c}\text { Tumor } \\
\text { weight } \pm \text { SD }\end{array}$} \\
\hline & P8 & P11 & & \\
\hline & & & $d$ & $m g$ \\
\hline Ki-ras2-infected & $5 / 5$ & $5 / 5$ & 14 & $520 \pm 56$ \\
\hline pLXSN-infected & $0 / 5$ & $0 / 5$ & - & - \\
\hline Noninfected & $0 / 5$ & $0 / 5$ & - & - \\
\hline
\end{tabular}

$10^{6}$ cells resuspended in $0.2 \mathrm{ml}$ PBS were injected subcutaneously. By $14 \mathrm{~d}$, all of the mice injected with Ki-ras2-infected cells developed tumors, while no tumors were detected in all other groups.

classical features of infiltrating colon adenocarcinomas. First, there were areas ranging from moderately to well-differentiated adenocarcinoma (Fig. 6, $A$ and $B$ ) and evidence of infiltration of the deep fascia and skeletal muscle (Fig. $6 C$ ). Nests of well-differentiated neoplastic cells forming gland-like structures were noted infiltrating the lymphatics $(D)$ and in the perineural spaces. In addition, in some areas the tumor cells grew as solid cords and induced a prominent desmoplastic reaction with characteristic deposition of a collagenous matrix (Fig. 6, $E$ and $F$ ). Collectively, the growth pattern and the invasive properties of these neoplastic cells are fully supportive of their gastroenteric origin and in agreement with biological behavior known for these tumors. Of interest, tumor growth in mice was accompanied by persistent overexpression of the exogenous Ki-ras as indicated by Northern blot analysis (Fig. 7).

The p53-/- epithelial cells (parental and carrying the LXSN vector) were nontumorigenic even when injected in SCID mice after in vitro growth for 32 passages (data not shown).

\section{Discussion}

The multistep nature of colorectal tumorigenesis is a welldefined process based on the dissection of a preferred order of mutations in the normal, premalignant, and malignant colon mucosa. However, it has been difficult to maintain in culture primary epithelial cells from colon crypts, and this has ham-

Table III. Evaluation of Tumor Growth in Syngeneic C57BL/6 Mice

\begin{tabular}{|c|c|c|c|c|}
\hline \multirow{2}{*}{$\begin{array}{l}\text { p53-/- colon } \\
\text { epithelial cells }\end{array}$} & \multicolumn{2}{|c|}{$\begin{array}{l}\text { Tumor incidence using } \\
\text { cells from the } 18 \text { th } \\
\text { and 20th passages }\end{array}$} & \multirow{2}{*}{$\begin{array}{l}\text { Latency } \\
\text { time }\end{array}$} & \multirow{2}{*}{$\begin{array}{c}\text { Tumor } \\
\text { weight } \pm S D\end{array}$} \\
\hline & P18 & $\mathrm{P} 20$ & & \\
\hline & & & $d$ & $m g$ \\
\hline Ki-ras2-infected & $5 / 5$ & $5 / 5$ & 14 & $485 \pm 62$ \\
\hline pLXSN-infected & $0 / 5$ & $0 / 5$ & - & - \\
\hline Noninfected & $0 / 5$ & $0 / 5$ & - & - \\
\hline
\end{tabular}

Injection of tumor cells in mice and assessment of tumor growth was as described in Table II 

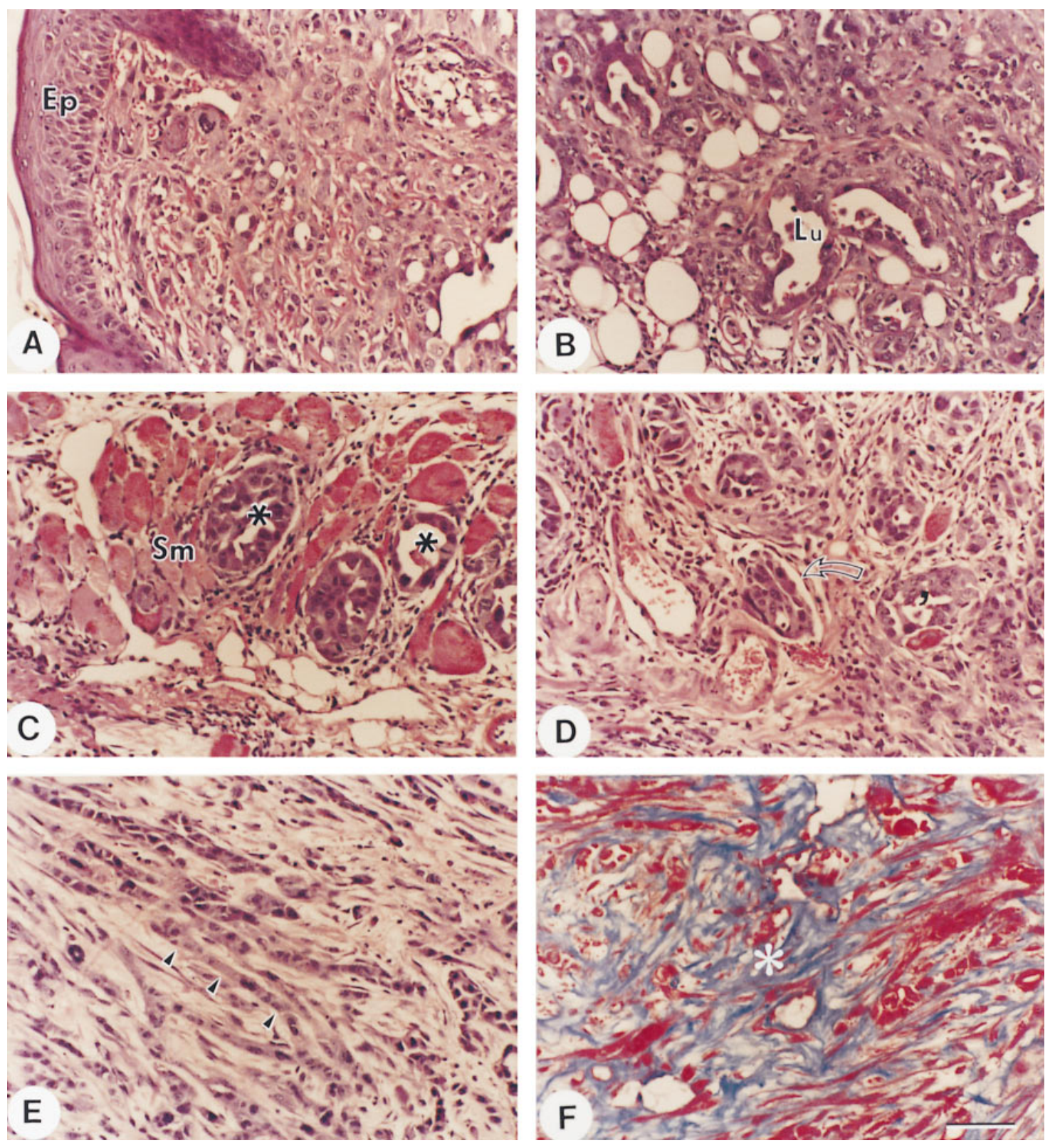

Figure 6. Light micrographs of subcutaneous tumor xenografts induced by colon epithelial cells carrying an oncogenic Ki-ras. $(A)$ Moderately to well-differentiated adenocarcinoma infiltrating the upper dermis. Ep, Epidermis. (B) A view of the deeper infiltration by the tumor cells forming irregular lumina $(L u)$ and invading the subcutaneous fibro-adipose tissues. $(C)$ Nests of well-differentiated neoplastic cells (asterisks) infiltrating bundles of skeletal muscle $(\mathrm{Sm})$. (D) Infiltration of lymphatic (curved arrow) by well-differentiated adenocarcinoma nodules. (E) Single-cell infiltration (arrowheads) within a desmoplastic tumor stroma. $(F)$ Trichrome-stained section showing a robust desmoplastic reaction stained in blue (asterisk) whereas the tumor cells and the noncollagenous portions of the tumor stroma are stained in red. Scale bar $=100 \mu \mathrm{m}$.

pered the direct assessment of the pathogenetic role of the various genetic lesions identified in colorectal cancer.

In this work, we have obtained cultures of primary epithelial cells from the colon crypts of p53-deficient mice. These cultures have been carried for several passages and are not tumorigenic, as indicated by their failure to form colonies in soft agar and tumors in immunodeficient or syngeneic hosts. In particular, after 32 passages, p53-deficient colon epithelial cells were still unable to form subcutaneous tumors in mice. By contrast, p53-deficient astrocytes appear to form tumors at earlier passages (24) and this correlates with an increase in the frequency of aneuploid cells.

Introduction of an activated Ki-ras gene in p53-deficient colon epithelial cells led to the rapid acquisition of a transformed phenotype as indicated by the ability of Ki-ras-infected cell to form colonies in soft agar, to exhibit high invasiveness in the in vitro assays designed for the assessment of this property, and to form tumors in immunodeficient and immunocompetent syngeneic hosts. The tumors formed in mice recapitulated the morphological features of colon adenocarcinomas and ex- 


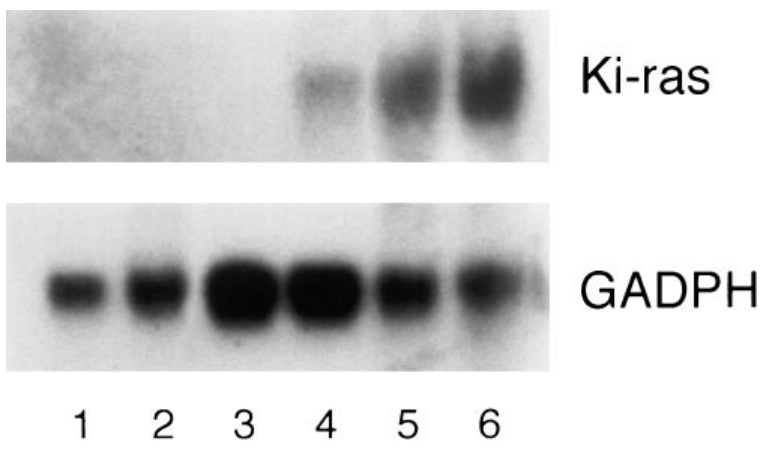

Figure 7. Northern blot analysis of Ki-ras expression in Ki-rasinduced tumors. Total RNA (10 $\mu \mathrm{g} / \mathrm{lane})$ was electrophoresed on a $1 \%$ denaturing agarose gel, transferred to Hybond-N membrane, and hybridized to a ${ }^{32} \mathrm{P}$-labeled 1.1-kb BamHI-PstI fragment of the oncogenic human Ki-ras2 cDNA according to standard procedures. After stripping, the filter was hybridized with a glyceraldehyde-3-phosphate dehydrogenase $(G A D P H)$ probe as used as control for RNA loading. Lanes are as follows: 1 , liver RNA from a p53-/- mouse; 2 , colon RNA from a p53 - /- mouse; 3, RNA from p $53-/-$ colon epithelial cells (18th passage); 4, RNA from Ki-ras-infected p53 -/- epithelial cells (18th passage); 5 and 6 , RNA from subcutaneous tumors in two mice. The blot hybridized with the mutant Ki-RAS probe was exposed $\sim 16 \mathrm{~h}$. After an exposure of $48 \mathrm{~h}$, a faint hybridization band was also detected in lane 3 .

hibited local invasion of the skeletal muscle, perineural spaces, and lymphatics. Of note, the tumor tissue of the xenografts exhibited elevated levels of Ki-ras expression, thus corroborating the causative role exerted by this oncogene upon a p53-deficient genetic background.

p53-deficient epithelial cells and the Ki-ras-transformed cells (at the 15th passage) were both highly aneuploid, as indicated by the identification of a normal chromosome number in only $20-25 \%$ of the metaphases that were examined (data not shown). Moreover, the frequency of polyploid metaphases was also indistinguishable in p53-/- and Ki-ras-transformed epithelial cells (data not shown). The frequency of aneuploid cells in p53 - /- epithelial cells is very similar to that reported for astrocytes (24) and embryo fibroblasts (25). Thus, it seems that the occurrence of secondary genetic abnormalities was not required for the Ki-ras-induced transformation of p53-deficient epithelial cells.

In this regard, loss of p53 function enables oncogenic proteins such as Myc, RAF, BCR/ABL, and RAS to exert their transformation potential $(15,26,27)$. In contrast, ectopic expression of oncogenic RAS in primary cells is associated with a transient stimulation of cell proliferation, followed by a permanent G1 arrest and features of early senescence (28). The appearance of this phenotype is accompanied by accumulation of wild-type p53 and the p16 cyclin inhibitor (28).

In our model of Ki-ras-induced neoplastic transformation of colon epithelial p53-/- cells, reintroduction of wild-type p53 markedly suppressed colony formation (Fig. 5). Thus, the results of this assay, which has long been used to investigate the tumor suppressor activity of p53 (13), are consistent with the essential role of a null p53 background for Ki-ras-induced colorectal tumorigenesis.

The findings described here are similar to those obtained with an epithelial cell line derived from the colon of a mouse carrying a loss-of-function mutation of the APC (adenomatous polyposis coli) gene and ecotypically expressing the v-Ha-ras gene (29). Loss of function mutations of the APC gene usually precede those involving Ki-ras and p53; however, colorectal tumorigenesis can also occur in the absence of APC mutations (2). It is likely that the synergy between a mutant APC allele and v-Ha-ras activates a tumorigenic pathway distinct from that involving an activated Ki-ras gene in the context of a null p53 phenotype. While the APC gene is clearly involved in the early stages of colorectal tumorigenesis, mutations at the p53 locus are often associated with disease progression $(1,2)$. Moreover, the effects of APC loss-of-function are largely restricted to colorectal epithelial cells (2), while inactivating mutations at the p53 locus led to perturbation of cell cycle activity and enhanced susceptibility to apoptosis in many cell types. Thus, these two models of colorectal tumorigenesis can be exploited to identify pathways of gene expression specific for distinct stages of tumorigenesis. Moreover, these models can be used to compare the therapeutic effects of conventional and novel antitumor drugs.

\section{Acknowledgments}

We thank Bodil Tuma for help with the electron microscopy studies.

Cinzia Sevignani was supported in part by a fellowship from the "A. Serra Foundation for Cancer Research." This work was supported in part by National Institutes of Health grants (CA-39481 and CA-46782) to R.V. Iozzo and B. Calabretta, respectively.

\section{References}

1. Fearon, E.R., and B. Vogelstein. 1990. A genetic model for colorectal tumorigenesis. Cell. 61:759-767.

2. Kinzler, K.W., and B. Vogelstein. 1996. Lessons from hereditary colorectal cancer. Cell. 87:159-170.

3. Siddiqui, K.M., and D.P. Chopra. 1984. Primary and long-term epithelial cell cultures from fetal normal colonic mucosa. In Vitro. 20:859-868.

4. Danes, B.S. 1985. Long-term-cultured colon epithelial cell lines from individuals with and without colon cancer genotypes. J. Natl. Cancer Inst. 75:261-267.

5. Vidrich, A., R. Ravindranath, K. Farsi, and S. Targan. 1988. A method for the rapid establishment of normal adult mammalian colonic epithelial cell cultures. In Vitro. 24:188-194.

6. Whitehead, R.H., A. Brown, and P.S. Bhathal. 1987. A method for the isolation and culture of human colonic crypts in collagen gels. In Vitro. 23:436-442.

7. Gibson, P.R., E. Van de Pol, L.E. Maxwell, A. Gabriel, and W.F. Doe. 1989. Isolation of colonic crypts that maintain structural and metabolic viability in vitro. Gastroenterology. 96:283-291.

8. Moyer, M.P., and J.B. Aust. 1984. Human colon cells: culture and in vitro transformation. Science. 224:1445-1447.

9. Whitehead, R.H., P.E. Van Eeden, M.D. Noble, P. Ataliotis, and P.S. Jat. 1993. Establishment of conditionally immortalized epithelial cell lines from both colon and small intestines of adult $\mathrm{H}-2 \mathrm{~Kb}$-tsA58 transgenic mice. Proc. Natl. Acad. Sci. USA. 90:587-591.

10. Donehower, L.A., M. Harvey, B.L. Slagle, M.J. McArthur, C.A. Montgomery, J.S. Butel, and A. Bradley. 1992. Mice deficient for p53 are developmentally normal but susceptible to spontaneous tumors. Nature. 356:215-221.

11. Shirasawa, S., M. Furuse, N. Yokayama, and T. Sasazuki. 1993. Altered growth of human colon cancer cell lines disrupted at activated Ki-RAS. Science. 260:85-88.

12. Goyette, M.C., K. Cho, C.L. Fasching, D.B. Levy, K.W. Kinzler, C. Paraskeva, B. Vogelstein, and E.J. Stanbridge. 1992. Progression of colorectal cancer is associated with multiple tumor suppressor gene defects, but inhibition of tumorigenicity is accomplished by correction of any single defect via chromosome transfer. Mol. Cell. Biol. 12:1387-1395.

13. Baker, S.J., S. Markowitz, E.R. Fearon, J.K. Wilson, and B. Vogelstein. 1990. Suppression of human colorectal cell growth by wild-type p53. Science. 243:912-915.

14. McCoy, M.S., C.I. Bargmann, and R.A. Weinberg. 1984. Human colon carcinoma Ki-ras2 oncogene and its corresponding protooncogene. Mol. Cell. Biol. 4:1577-1582.

15. Skorski, T., M. Nieborowska-Skorska, P. Wlodarski, D. Perrotti, R. Martinez, M.A. Wasik, and B. Calabretta. 1996. Blastic transformation of p53- 
deficient bone marrow cells by $\mathrm{p} 210^{\mathrm{bcr} / a b l}$ tyrosine kinase. Proc. Natl. Acad. Sci. USA. 93:13137-13142.

16. Miller, A.D., and G.J. Rosman. 1989. Improved retroviral vectors for gene transfer and expression. Biotechniques. 9:980-985.

17. Markowitz, D., S. Goff, and A. Bank. 1988. A safe packaging line for gene transfer: separating viral genes on two different plasmids. J. Virol. 62: $1120-1124$

18. Huttner, K.M., J.A. Barbosa, G.A. Scangos, D.D. Pratcheva, and F.H. Ruddle. 1981. DNA-mediated gene transfer without carrier DNA. J. Cell Biol. 91:153-156.

19. Danielson, K., A. Martinez-Hernandez, J.R. Hassell, and R.V. Iozzo. 1992. Characterization of a basement membrane-producing cell line from the EHS tumor. Matrix. 11:22-35.

20. Iozzo, R.V. 1984. Biosynthesis of heparan sulfate proteoglycan by human colon carcinoma cells and its localization at the cell surface. J. Cell Biol. 99: 403-417.

21. George, D.L., A.F. Scott, S. Trusko, B. Glick, E. Ford, and D.J. Dorney. 1985. Structure and expression of amplified cKi-ras gene sequences in Y1 mouse adrenal tumor cells. EMBO (Eur. Mol. Biol. Organ.) J. 4:1199-1203.

22. Sambrook, J., E.F. Fritsch, and T. Maniatis. 1989. Molecular Cloning: A Laboratory Manual. 2nd ed. Cold Spring Harbor Laboratory, Cold Spring Harbor, NY.
23. Fawcett, D.W. 1981. The Cell. W.B. Saunders, Co., Philadelphia, PA.

24. Yahanda, A.M., J.M. Bruner, L.A. Donehower, and R.S. Morrison. 1995. Astrocytes derived from p53-deficient mice provide a multistep in vitro model for development of malignant gliomas. Mol. Cell. Biol. 15:4249-4258.

25. Harvey, M., A.T. Sands, R.S. Weiss, M.E. Hegi, R.W. Wiseman, P. Pantazis, B.C. Giovanella, M.A. Tainsky, A. Bradley, and L.A. Donehower. 1993 In vitro growth characteristics of embryo fibroblasts isolated from p53-deficient mice. Oncogene. 8:2457-2467.

26. Metz, T., A.W. Harris, and J.M. Adams. 1995. Absence of p53 allows direct immortalization of hematopoietic cells by the myc and raf oncogenes. Cell. 82:29-36.

27. Tanaka, N., M. Ishihara, M. Kitagawa, H. Harada, T. Kimura, T. Matsuyama, M.S. Lamphier, S. Aizawa, T.W. Mak, and T. Taniguchi. 1994. Cellular commitment to oncogene-induced transformation of apoptosis is dependent on the transcription factor IRF-1. Cell. 77:829-839.

28. Serrano, M., A.W. Lin, M.E. McCurrach, D. Beach, and S.W. Lowe. 1997. Oncogenic ras provokes premature cell senescence associated with accumulation of $\mathrm{p} 53$ and $\mathrm{p} 16^{\mathrm{INK} \alpha}$. Cell. 88:593-602.

29. D'Abaco, G.M., R.H. Whitehead, and A.W. Burgess. 1996. Synergy between Apcmin and an activated ras mutation is sufficient to induce colon carcinomas. Mol. Cell. Biol. 16:884-898. 